\title{
Editorial
}

\section{Water Remediation}

\section{Reyna Natividad-Rangel, ${ }^{1}$ Manuel A. R. Rodrigo, ${ }^{2}$ Julie J. M. Mesa, ${ }^{3}$ and Rosa M. G. Espinosa ${ }^{1}$}

\author{
${ }^{1}$ Centro Conjunto de Investigación en Química Sustentable UAEM-UNAM, Universidad Autónoma del Estado de México, \\ km 14.5 Carr., Toluca-Atlacomulco, 50200 Toluca, MEX, Mexico \\ ${ }^{2}$ Department of Chemical Engineering, Faculty of Chemical Sciences Technology, Universidad de Castilla-La Mancha, \\ Edificio Enrique Costa Novella, Campus Universitario S/N, 13071 Ciudad Real, Spain \\ ${ }^{3}$ Escuela de Ciencias Químicas, Universidad Pedagógica y Tecnológica de Colombia (UPTC), Avenida Central del Norte, \\ Tunja, Boyacá, Colombia
}

Correspondence should be addressed to Reyna Natividad-Rangel; reynanr@gmail.com, Manuel A. R. Rodrigo; manuel.rodrigo@uclm.es, Julie J. M. Mesa; jjuliejoseane@hotmail.com, and Rosa M. G. Espinosa; rosamarigo@gmail.com

Received 13 December 2016; Accepted 13 December 2016; Published 26 April 2017

Copyright (C) 2017 Reyna Natividad-Rangel et al. This is an open access article distributed under the Creative Commons Attribution License, which permits unrestricted use, distribution, and reproduction in any medium, provided the original work is properly cited.

The satisfaction of human needs has made past and current generations enroll in an unsustainable development because of the great negative effects that their activities exert on environment and therefore on the available natural resources. Consequently, this compromises the satisfaction of the needs of future human generations. In this context, pollution associated with anthropogenic species and heavy metals is becoming a serious environmental problem not only because of the important damage that causes to the environment, that includes among other aspects the loss of biodiversity and severe changes in the ecosystems, but also because it may prevent the use of water reservoirs to produce drinking water. Thus, both types of pollutants are associated with serious illnesses and their occurrence in water may be prevented. As for many other water treatment technologies, costs associated with their removal are directly related to the concentration of the species in the water matrix and the removal of highly polluted wastewater is much more cost-effective, where the concentrations can be even of hundreds of ppm rather than the treatment of drinking water reservoirs, where their concentrations are of only several ppb or even ppt (very low for an efficient treatment but high enough to produce health problems). For this reason, it is of paramount importance to develop technologies able to efficiently deplete this type of pollutants from their typical sources (frequently industrial wastes).
Through the fourteen papers contained in this special issue dedicated to water remediation, different and interesting approaches to improve the efficiency of a water treatment process are discussed and so cutting-edge technology to face this important problem is also presented. The approaches include either the novel modification of sorbents and catalysts or the integration of biological and physicochemical processes. In this sense, electrochemical, photochemical, adsorption, and ion exchange processes are evaluated alone and combined with biological and other physicochemical processes, like ozonation, in order to develop efficient water treatment technologies.

The adsorption related manuscripts indicate that currently the synthesis and application of sorbent materials is still useful and effective in the removal of heavy metals $(\mathrm{Pb}, \mathrm{Hg}$, $\mathrm{Zn}$, and $\mathrm{Cu}$ ), dyes, phenolic compounds, and other organic pollutants from water sources. It is worth noticing that an interesting trend can be observed on using biomass and agricultural waste as raw materials of sorbents, thus giving to this waste an added value. The sorbents' successful modifications reported are both physical and chemical, although the latter seems to exert a greater positive effect on adsorption capability than the former.

Photochemical processes (heterogeneous photocatalysis and photofenton) are also included in this issue mainly due to the important contribution of this technology in 
environmental remediation. Different authors around the world have studied photocatalysis based on titania and other novel materials, showing that this treatment is efficient, suitable, and less expensive in water remediation. It is also important to note that this technology is not selective; it means that by photocatalysis different pollutants present in complex matrix samples can be removed, avoiding the use of additional treatments. An important challenge within photocatalysis, however, is to be able to conduct such a process under solar light and this depends mainly on the photocatalyst. In this sense, a manuscript related to the synthesis and application of a silver modified vanadia photocatalyst is included. Interestingly enough, such a material is demonstrated to be active under simulated solar light.

Generally speaking, the presented results range from lab to pilot scale and from synthetic to actual industrial wastewater (paraformaldehyde production chemical plant, truck wash water facility, and $\mathrm{Hg}$ contaminated groundwater) treatment.

Finally, it is worth pointing out that the results shown demonstrate that the assessed materials and technologies are efficient and, more important, that it is still possible to look for synergism between technologies looking for cheaper and more efficient water treatment technologies. Conclusions reached are sound and they indicate that despite the great achieved progress so far, this topic is still open for discussion in the next decades and may importantly contribute to the sustainability of processes.

\author{
Reyna Natividad-Rangel \\ Manuel A. R. Rodrigo \\ Julie J. M. Mesa \\ Rosa M. G. Espinosa
}



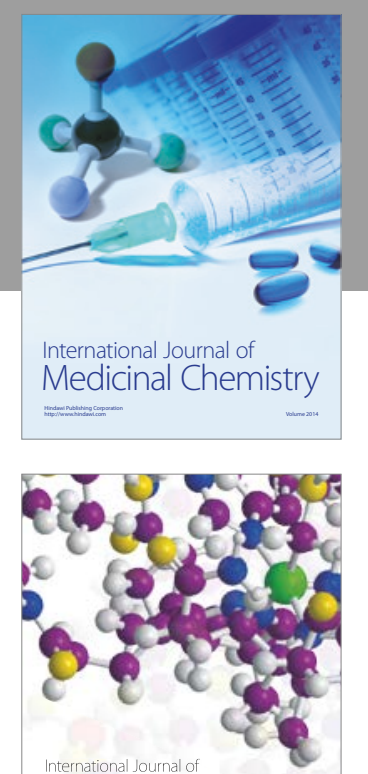

Carbohydrate Chemistry

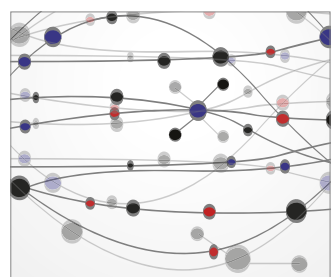

The Scientific World Journal
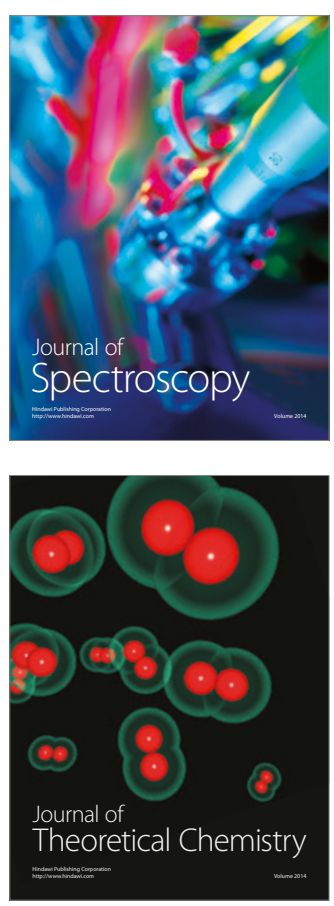
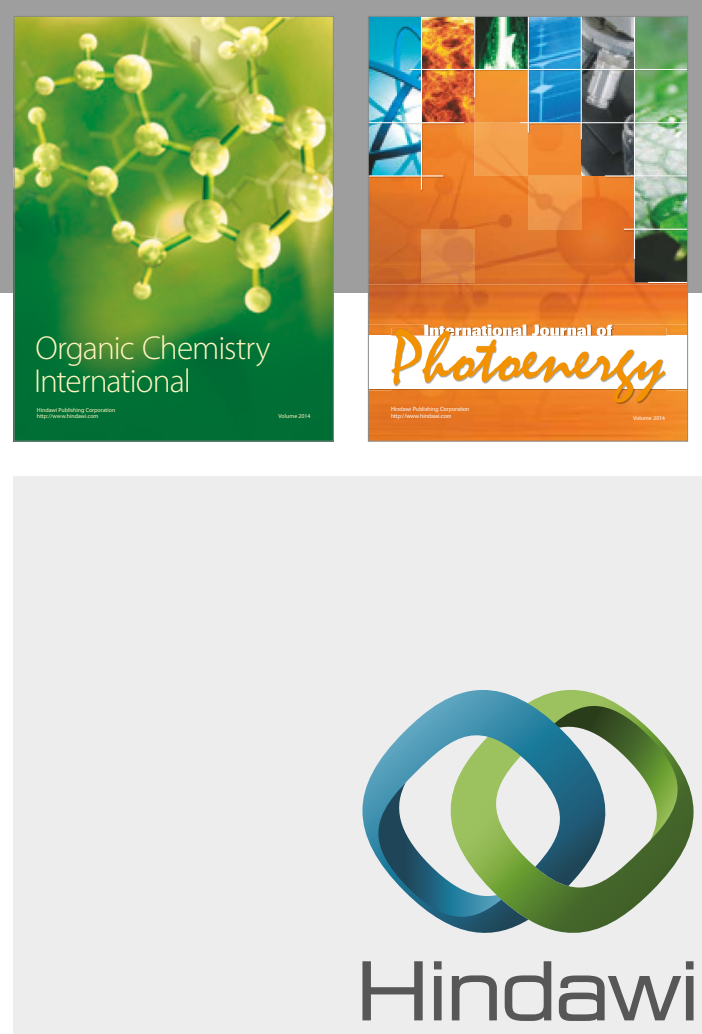

Submit your manuscripts at

https://www.hindawi.com

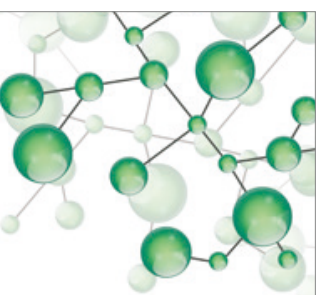

International Journal of

Inorganic Chemistry

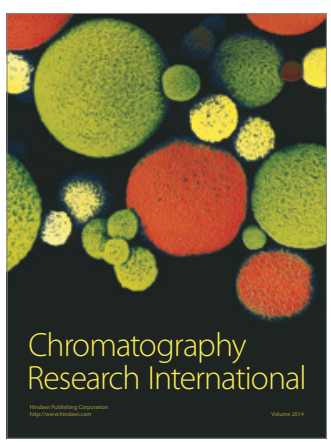

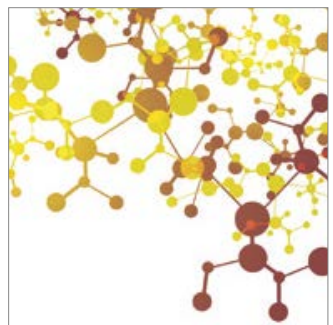

Applied Chemistry
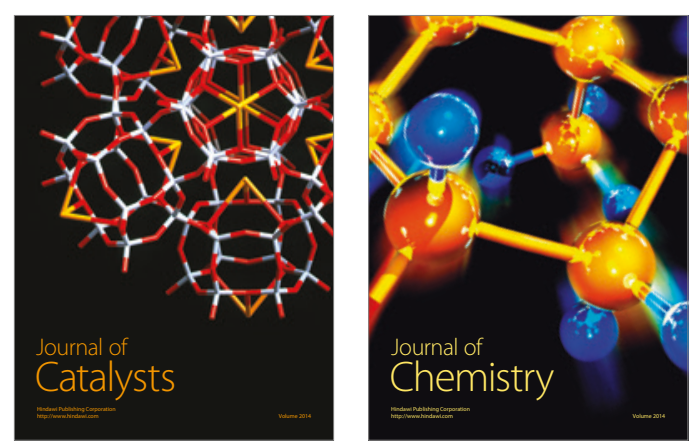
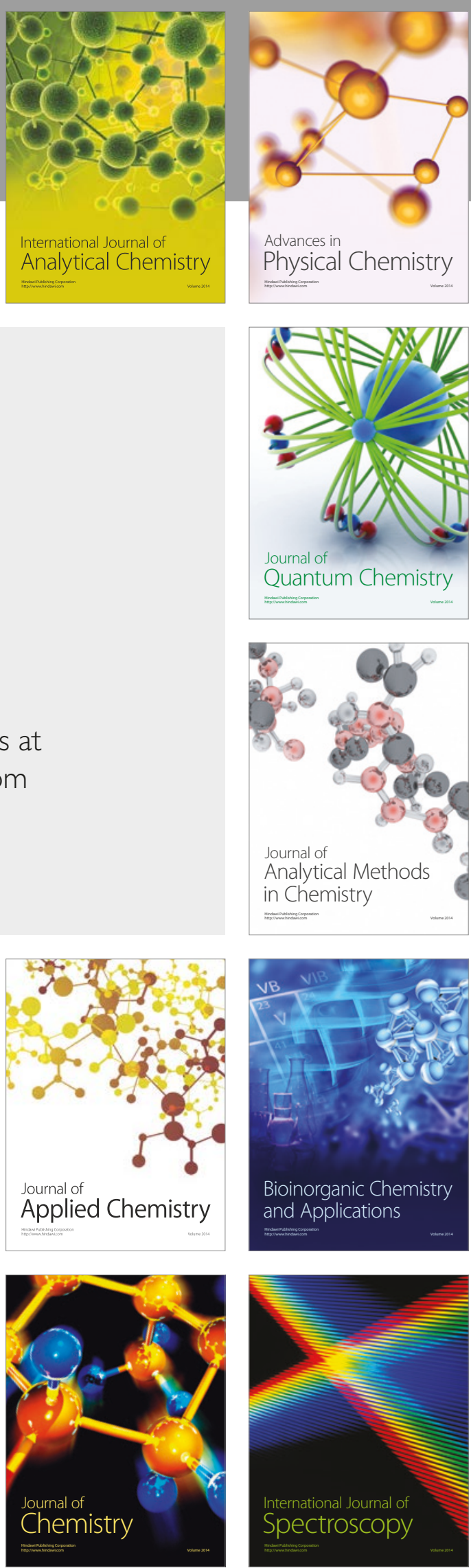